\title{
Experiences in Routine Genetic Analysis of Hereditary Hemorrhagic, Thrombotic, and Platelet Disorders
}

\author{
B. Pezeshkpoor $r^{1,2}$ J. Oldenburg ${ }^{1,2}$ A. Pavlova ${ }^{1,2}$ \\ ${ }^{1}$ Institute of Experimental Hematology and Transfusion Medicine, \\ University Hospital Bonn, Medical Faculty, University of Bonn, Bonn, \\ Germany \\ ${ }^{2}$ Center for Rare Diseases Bonn (ZSEB), University Clinic Bonn, Bonn, \\ Germany \\ Address for correspondence PD Dr. rer. nat. B. Pezeshkpoor, PhD, \\ Institute of Experimental Hematology and Transfusion Medicine, \\ University Hospital Bonn, Medical Faculty, University of Bonn, Bonn, \\ Germany (e-mail: behnaz.pezeshkpoor@ukbonn.de).
}

Hamostaseologie 2022;42(Suppl 1):S5-S12.

Abstract

Keywords
- platelet
pathology/inherited
- acquired
- thrombosis
- inherited coagulation
disorders
- gene mutations
- diagnosis
management

Zusammenfassung
Hemostasis is a complex and tightly regulated system that attempts to maintain a homeostatic balance to permit normal blood flow, without bleeding or thrombosis. Hemostasis reflects the subtle balance between procoagulant and anticoagulant factors in the pathways of primary hemostasis, secondary hemostasis, and fibrinolysis. The major components in this interplay include the vascular endothelium, platelets, coagulation factors, and fibrinolytic factors. After vessel wall injury, the subendothelium is exposed to the blood stream, followed by rapid activation of platelets via collagen binding and von Willebrand factor-mediated platelet adhesion to the damaged vessel wall through platelet glycoprotein receptor Ib/IX/V. Activated platelets change their shape, release bioactive molecules from their granules, and expose negatively charged phospholipids on their surface. For a proper function of this process, an adequate number of functional platelets are required. Subsequently, a rapid generation of sufficient amounts of thrombin begins; followed by activation of the coagulation system and its coagulation factors (secondary hemostasis), generating fibrin that consolidates the platelet plug. To maintain equilibrium between coagulation and anticoagulation, the naturally occurring anticoagulants such as protein $C$, protein $\mathrm{S}$, and antithrombin keep this process in balance. Deficiencies (inherited or acquired) at any level of this fine-tuned system result in pathologic bleedings or increased hypercoagulability states leading to thrombosis. This review will focus on genetic diagnosis of inherited bleeding, thrombotic, and platelet disorders, discussing strengths and limitations of existing diagnostic settings and genetic tools and highlight some important considerations necessary for clinical application.

Die Hämostase ist ein komplexes und streng reguliertes System, das dazu dient ein homöostatisches Gleichgewicht aufrecht zu erhalten und einen normalen Blutfluss ohne Blutungen oder Thrombosen zu ermöglichen. Die Hämostase stellt das fein balancierte Gleichgewicht zwischen gerinnungsfördernden und gerinnungshemmenden Faktoren in der primären Hämostase, der sekundären Hämostase und der Fibrinolyse dar. Zu den wichtigsten Komponenten in diesem Zusammenspiel gehören received

November 8, 2021

accepted after revision

December 20, 2021 (c) 2022. Thieme. All rights reserved.

Georg Thieme Verlag KG,

Rüdigerstraße 14,

70469 Stuttgart, Germany
DOI https://doi.org/

10.1055/a-1726-4793.

ISSN 0720-9355. 


Schlüsselwörter
- Blutplättchen
Krankheitsbild/vererbt
- erworben
- Thrombose
- angeborene
Blutgerinnung-
sstörungen
- Genmutationen
- Diagnosemana-
gement

das Gefäßendothel, die Thrombozyten, die Gerinnungsfaktoren und die fibrinolytischen Faktoren. Nach einer Verletzung der Gefäßwand wird das Subendothel dem Blutstrom ausgesetzt, gefolgt von einer raschen Aktivierung der Thrombozyten durch Kollagenbindung und VWF-vermittelte Thrombozytenadhäsion an der beschädigten Gefäßwand durch den Thrombozyten-Glykoproteinrezeptor Ib/IX/V. Aktivierte Thrombozyten verändern ihre Form, setzen bioaktive Moleküle aus ihren Granula frei und legen negativ geladene Phospholipide auf ihrer Oberfläche frei. Dieser Prozessder primären Hämostase setzt eine ausreichende Anzahl funktionstüchtiger Thrombozyten voraus. Anschließend beginnt eine rasche Bildung großer Mengen von Thrombin, gefolgt von einer Aktivierung der prokoagulatorischen Gerinnungsfaktoren (sekundäre Hämostase), wodurch Fibrin entsteht, das den initialen Thrombozytenpfropf verfestigt. Um das Gleichgewicht zwischen Gerinnung und Antikoagulation aufrechtzuerhalten, halten die natürlich vorkommenden Antikoagulanzien wie Protein C, Protein S und Antithrombin diesen Prozess im Gleichgewicht. Defizite (vererbt oder erworben) auf irgendeiner Ebene dieses so fein abgestimmten Systems führen zu pathologischen Blutungen oder einer erhöhten Hyperkoagulabilität, die zu Thrombosen führt. Diese Übersichtsarbeit fokussiert die genetische Diagnose von vererbten Blutungs-, Thrombose- und Thrombozytenstörungen, wobei die Stärken und Limitationen bestehender diagnostischer Verfahren und genetischer Techniken erörtert und wichtige Überlegungen für die klinische Anwendung gegeben werden.

\section{Relevance of Genetic Testing of Inherited Bleeding, Thrombotic, and Platelet Disorders}

Inherited bleeding or thrombotic diseases as well as platelet disorders (IBTPDs) are a heterogeneous group of rare conditions caused by genetic variants in a large number of genes, characterized by a high susceptibility to spontaneous or prolonged bleeding or increased risk for a thrombotic event. Inherited bleeding disorders (IBDs), representing a significant fraction of all the bleeding diatheses, can be further divided into coagulation disorders, affecting either plasma coagulation factors or platelet factors/proteins, affecting formation and/or function of platelets. ${ }^{1}$ Although a common background, these three groups differ fundamentally in clinical presentation, frequency, and treatment. Despite the advance in routine laboratory settings, the diagnosis of IBTPD remains cumbersome.

IBDs, caused by defects in genes that code for plasma coagulation factors, include the common disorders such as hemophilia A, hemophilia B, and factor VII deficiency ( Fig. 1). ${ }^{1-3}$ Deficiencies of the remaining coagulation pathway factors, fibrinogen, factor (F) II, FV, combined FV and FVIII, FX, FXI, FXIII, and congenital deficiency of vitamin Kdependent factors, are generally less common, although some ethnic populations have higher frequency of affected individuals due to founder variants. ${ }^{3-5}$ The classical diagnostic trait for coagulation bleeding disorders is usually based on a clinical interpretation of bleeding symptoms as well as laboratory testing. ${ }^{3,6}$ The first-line laboratory tests (prothrombin time, the activated partial thromboplastin time, the thrombin time, and fibrinogen) are mostly used for screening of patients with suspected bleeding disorders. Although abnormalities of the first-line coagulation assays may be suggestive, they do not allow an accurate identification of the nature of the disorder and should be followed by single factor analysis. This second-line tests may be extended by a genetic analysis, which can assist in the identification and specificity of the defect responsible for the disease symptoms, make the diagnosis clear, and allow an ultimate classification of disease severity. ${ }^{2}$ Though the diagnosis is rather straightforward, there are bleeding conditions, which still remain unresolved with the standard diagnostic settings and create difficulties in treatment decision making. Especially relevant for this are the mild bleeding phenotypes where diagnostic workup tends to be based on local practices rather than guided by sound clinical, laboratory, or genetic criteria. Representative examples are patients with type 1 von Willebrand disease (VWD), mild hemophilia or hemophilia carriers, and heterozygous deficiencies of specific clotting factors. Typically, a severe form of an autosomal recessive disorder is extremely rare, whereas the heterozygote carriers with mild expression of the phenotype could be frequent. FXIII deficiency is a good example for this condition. ${ }^{7,8}$ In Germany, approximately 40 patients suffer from a severe form of FXIII deficiency, indicating that in these patients both alleles are either homozygous or compound heterozygous affected. However, according to the mendelian trait rules, this translates to a frequency of heterozygous carriers of 1:1,000, which represents approximately 80,000 individuals in a population of 80 million. Thus, heterozygote carriers may exhibit only mild symptoms and most will remain undiagnosed throughout life. 


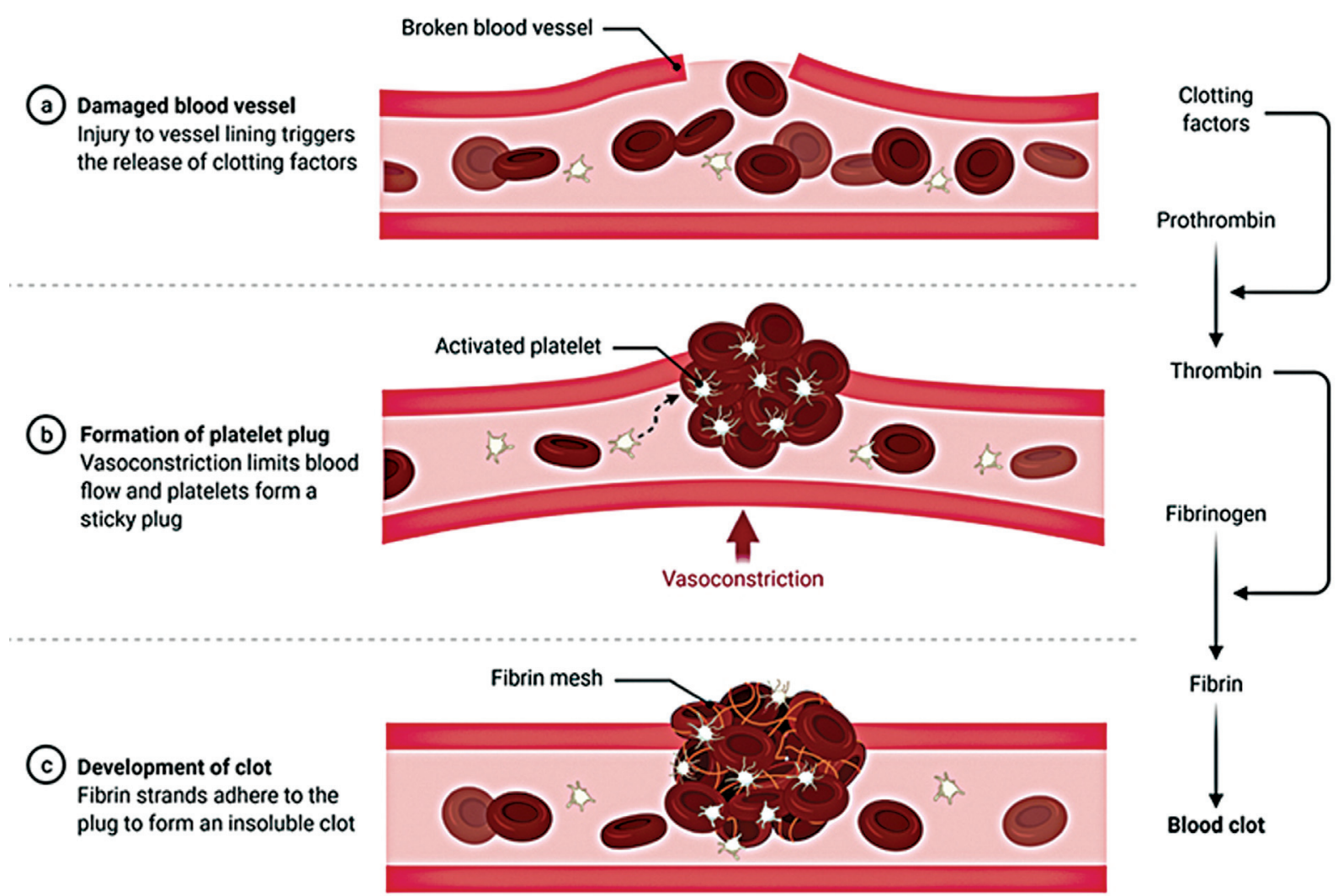

Fig. 1 Overview of hemostasis. The major components in this interplay include the vascular endothelium, platelets, the coagulation factors, and fibrinolytic factors (created with BioRender.com). [rerif]

The second group of IBDs is associated with qualitative and quantitative disorders of platelets. Although phenotypeguided diagnosis in some inherited platelet disorders (IPDs), as Bernard-Soulier syndrome, Glanzmann thrombasthenia, and Hermansky-Pudlak syndrome, can be straightforward due to the severity of the bleeding or the syndromic nature, in most IPDs the diagnosis is much more challenging owing to the high disease heterogeneity and indistinct clinical and laboratory features. ${ }^{9-11}$ Additionally, the diagnosis is complicated when acquired platelet disorders (due to drugs, liver or kidney disease, hematologic disorders, and other systemic diseases), which are more frequent than IPDs, are taken into consideration. ${ }^{12}$ In nonsyndromic patients with IPDs, particularly those with mild bleeding, the diagnosis is often questionable and may lead to misinterpretation. Immune thrombocytopenic purpura, for instance, was misdiagnosed in $42 \%$ of subjects where MYH9-related disorders were genetically established. ${ }^{13}$ In other cases, the pathogenic alterations in distinct genes, associated with different diseases, have similar clinical presentation as mild bleeding tendency, mild thrombocytopenia, and normal platelet size (von Willebrand factor [VWF] type $2 \mathrm{~B}$ ). ${ }^{14}$ This makes the diagnosis inconclusive even with specific laboratory analyses and only the genetic investigations can provide the final accurate diagnosis. Consequently, many IPDs remain underdiagnosed, despite the many proposed diagnostic algorithms, making it difficult to estimate the total prevalence.

Thrombophilia is a hypercoagulable state that may have an inherited or acquired basis and is associated with venous rather than arterial thrombosis. As a multifactorial condition, the convergence of underlying genetic predisposition and acquired environment factors are difficult to be distinguished. The abnormalities associated with an inherited predisposition to thrombosis include those that either cause insufficient inhibition of the blood clotting cascade (through loss of function variants) or cause increased clotting activity (through gain of function variants). Two frequent pathogenic variants in F5 (factor V Leiden) and F2 (prothrombin variant) genes contribute to the hypercoagulable state in the majority of cases. A deficiency of antithrombin, protein $\mathrm{C}$, protein $\mathrm{S}$, plasminogen, and dysfibrinogenemia is less common in inherited thrombophilia. ${ }^{15-18}$

To achieve an accurate diagnosis, which facilitates better clinical care, prognosis, and preventive treatments, genetic analyses are taking greater place in the routine diagnostic settings. In abnormal phenotypes, genetic assessment enables ruling out diseases that may have been acquired or thought to be caused by exposure to known environmental risk factors. Especially beneficial genetic testing is in precise diagnostic of milder bleeding phenotypes contributing to a correct treatment decision making. Genetic testing can be exclusively useful for differential diagnosis in cases with similar clinical features but different treatment options such as mild hemophilia A versus VWD type 2N, VWD type $2 \mathrm{~B}$ versus platelet-type VWF. In some cases, type of genetic defect and its localization along the gene could predict the mode of inheritance (autosomal dominant forms of Glanzmann thrombasthenia), severity of bleedings, and 
expression of different disease-related complications (likelihood of renal disease and deafness in $\mathrm{MYH9}){ }^{19}$

Furthermore, in the last several years, molecular diagnosis becomes crucial for identifying patients with IPD at a high risk of malignancy and an increased risk for associated pathologies, such as myelofibrosis (NBEAL2), renal insufficiency (MYH9), and hematological malignancies $(R U N X 1) .{ }^{20}$ Additionally, a benefit from diagnosis at genetic level is that it enables more precise classification of IPD, allowing better prediction of clinical risk of bleeding and syndromic comorbidities (-Fig. 2).

\section{Detection of Pathogenic Variants in Inherited Bleeding, Thrombotic, and Platelet Disorders}

Until recently, DNA analyses have been largely restricted to the analysis of candidate genes, selected according to the patient's clinical and laboratory phenotype and suspected diagnosis. While for some patients the selection of candidate genes is straightforward (such as for hemophilia A or B), for other patients, especially for some platelet disorders, this is

\section{Diagnostic workflow of inherited bleeding, platelet and thrombotic disorders}

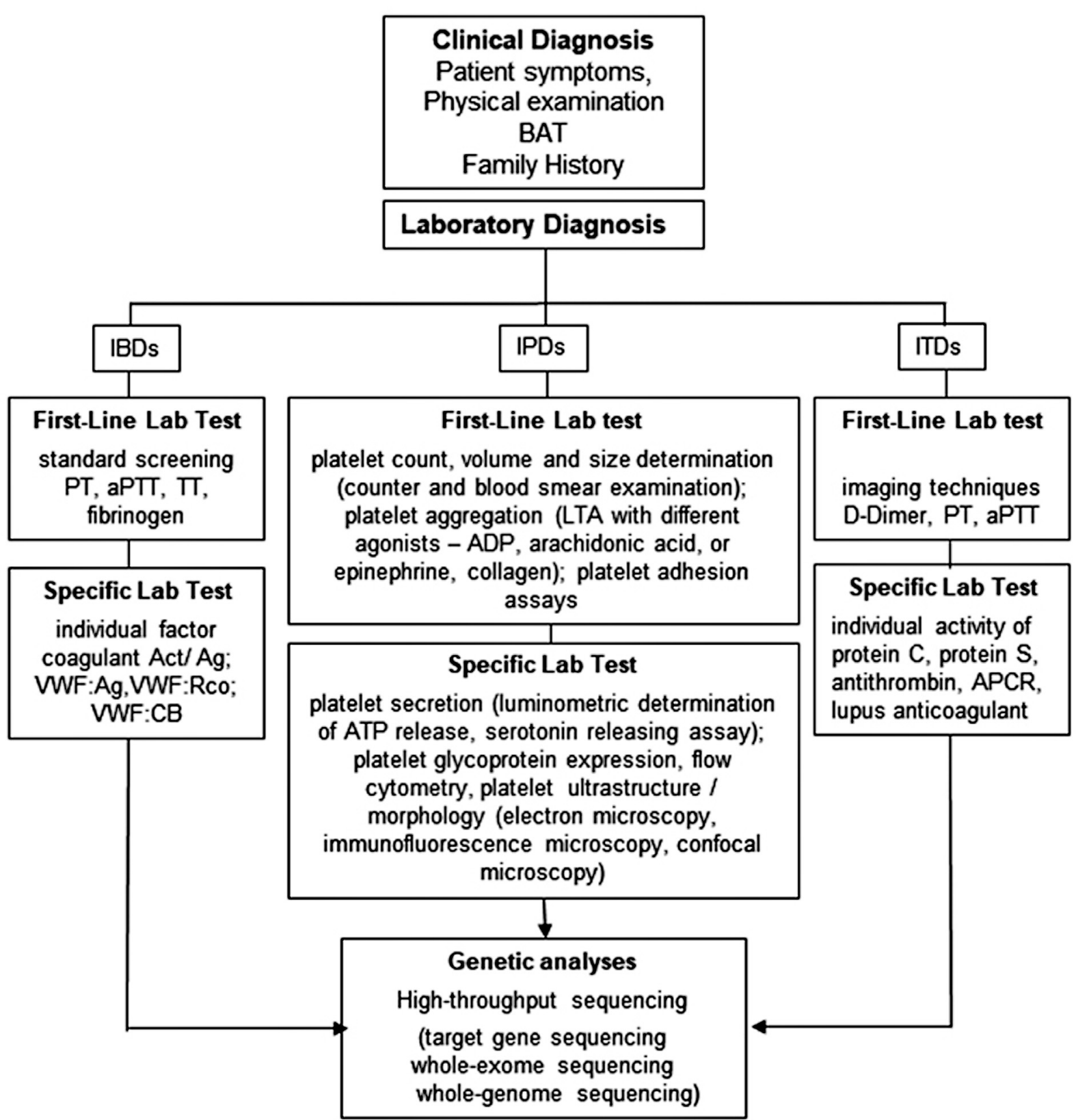

Fig. 2 Flowchart of a laboratory assessment in a patient suspected for IBTPDs. IBDs, inherited bleeding disorders; IPDs, inherited platelet disorders; ITDs, inherited thrombotic disorders; PT, prothrombin time; APTT, activated partial thromboplastin time; TT, thrombin time; Act, activity; Ag, antigen; VWF, von Willebrand factor; VWF:CB, VWF collagen binding activity; VWF:Rco, von Willebrand factor ristocetin cofactor; LTA, light transmission aggregometry; ADP, adenosine diphosphate; APCR, activated protein C resistance; BAT, bleeding assessment tool. 
not the case. A common feature for the many IPDs is thrombocytopenia combined with mild bleedings without any other clinical signs, which makes it difficult to differentiate between the distinct clinical units. Nevertheless, the genetic background shows great heterogeneity. A good example summarizes patients with thrombocytopenia due to genetic variants in different genes as ANKRD26; CYCS, ETV6, or SLFN14). Additionally some clinical phenotypes (such as Hermansky-Pudlak syndrome) can be caused by at least nine different genes (HPS1, AP3B1, HPS3, HPS4, HPS5, HPS6, DTNBP1, BLOC1S3, AP3D1) which would require multiple candidate genes to be tested.

In the last several years, different testing strategies have been employed to achieve a molecular diagnosis including sequencing of targeted suspected genes, sequencing a panel of genes related to a specific disease or phenotype. Broader strategies are whole-exome sequencing (WES) or wholegenome sequencing (WGS), which is more agnostic to the diagnosis or potential genes involved. ${ }^{21}$ Despite the undisputed importance of genetic results, molecular analyses of IBTPD have been performed as the last step in the workflow of the diagnosis of these diseases. Nevertheless, the genetic testing allows a final and clear diagnosis that may facilitate the choice of the optimal treatment regimen. ${ }^{9,10,22-24}$

Sanger sequencing has historically been the reference standard method for the detection of pathogenic variants in IBTPDs, but the technology is time consuming and work intensive. $^{3,6,25}$ This restricts the application of Sanger sequencing to small genomic regions containing individual genes of interest. Therefore, Sanger sequencing is best suited to situations where single or small numbers of candidate genes can be selected because of characteristic clinical or laboratory phenotypes that are highly suggestive of a specific disorder (most coagulation factor deficiencies, where the reduced factor activity directly points to the affected gene). In these situations, achieving genetic diagnosis by Sanger sequencing can be seen as confirming the clinically and pathologically suggested diagnosis based on phenotype testing alone. Diagnostic ability of Sanger sequencing is rather limited in disorders with uncertain phenotype-based diagnosis, detection of combined deficiencies, and disorders coded with more than one locus (e.g., Hermansky-Pudlak syndrome). The technique itself provides data exclusively for the coding regions and close intron/exon boundaries leaving variants outside these regions undetectable. Thus, a significant number of patients can never get a conclusive molecular diagnosis leading to frustration in both patients and physicians. $^{6,26}$

The implementation of high-throughput sequencing (HTS) in diagnostic flow allows for the testing of a large number of genes in parallel; greatly reduces the workload, turnaround time, and costs; and provides an affordable DNAbased test to diagnose patients suspected of having a known inherited IBTPD.

Three different HTS methods can be used for diagnostics and research: targeted (panel) sequencing (TS), WES, and WGS. ${ }^{1}$ All these technologies employ fragmented genomic DNA samples that undergo an amplification step using PCR- based technologies. Despite utilizing the same basic technology, these three techniques differ fundamentally in amount of data generated for each sample, in the way that nucleotide sequence is detected and outputted and the ability of identification of new genes. While WES and WGS can analyze every gene in the human genome, only a specific set of disease or phenotype-associated genes (typically a group of $10-100$ genes) is sequenced using TS. Technically, panels offer better base-pair coverage, shorter run times, lower costs, and better dataset handling. Thus, TS is rapidly becoming a valuable and more suitable tool for clinical diagnostic. $^{2,27}$ This approach is usually applied for the diagnosis of disorders for which there are several candidate genes that cannot easily be resolved using clinical and laboratory phenotypes and make it useful to diagnose disorders with genetic and clinical heterogeneity as IBTPDs. The genomics scientific subcommittee of the International Society on Thrombosis and Haemostasis maintains a list of genes that are considered to be proven to cause hemostatic disease at https://www.isth.org/page/GinTh_GeneLists. This list contains 101 genes of which 22 are coagulation factor genes, 11 are thrombotic, and 68 cause platelet abnormalities. ${ }^{28}$ Thus, clinically orientated services in the diagnosis of IBTPDs are predominantly based on TS, while whole-genome analysis is mostly used in research.

While HTS has enabled access to genes for which testing was not previously feasible in a clinical setting, the efficiency of simultaneous multigene testing also exhibits some disadvantages and limitations.

\section{Secondary Findings}

Parallel to the results of the genetic analyses for a specific disease, the HTS methods allow the detection of unexpected, secondary findings. A secondary finding is defined as a genomic variant of potential medical value that is unrelated to the primary reason for testing. Compared with WES and WGS, the likelihood of detecting a secondary finding is relatively low with TS diagnostic, where the genes used in the panels are of relevance only for a particular group of disease. Nevertheless, with the advent of HTS in the routine clinical diagnostic, secondary findings are more and more likely to be diagnosed. A fundamental question remains whether to report findings at loci not directly relevant to the phenotype under investigation. This is a rather difficult question and to make a decision, several aspects have to be taken into consideration: (1) if the detected secondary finding is associated with a clinical phenotype and particularly with a severe one; (2) the mode of inheritance-autosomal recessive or autosomal dominant. Majority of bleeding disorders of similar severity have an autosomal recessive mode of inheritance and secondary findings do not need to be reported; (3) pathogenicity of the secondary findings. Variants of uncertain significance are not recommendable to be reported. It is essential to decide how to report coincidental findings of gene defects with a potential risk for leukemia or cancer or gene defects likely to predict other major illnesses. 
Genomic testing in minors raises particularly complex questions related to the possibility of incidental or secondary findings. ${ }^{29}$ It is a difficult decision and several aspects have to be taken into consideration: whether knowing the genetic defect will be of benefit to the child and parents and what interventions are available and can be taken to reduce the risk of the disease development. ${ }^{30,31}$ Most importantly, these results should be communicated in the context of a genetic counseling of the patient.

\section{Overall Diagnostic Rate}

The chance of finding a potentially pathogenic variant depends on the type of hemostatic disorders under investigation. In individuals in whom despite medical and family history, physical and diagnostic examination, no clear indications of genetic disorder exist, the final diagnosis is a challenging scenario.

Our experience, with more than 3,500 patients with hemostatic disorders, shows that overall, the diagnostic rate is much higher in patients who are well phenotypically and laboratory characterized. A onetime measured deficiency should be confirmed by a second laboratory analysis before planning a genetic testing. The diagnostic rate reaches more than $95 \%$ in well-defined genetic disorders, but approximately 50 to $70 \%$ in less defined conditions, similar to those reported in the ThromboGenomics study (67\%). ${ }^{27}$ In patients with IPDs with not well-defined phenotype and similar clinical symptoms to acquired forms, the overall diagnostic rate is relatively low. Recently published studies attempt to estimate the overall diagnostic rate, but the reported data are difficult to be compared due to differences in study design (platelet disorders, coagulation disorders, and bleeding of unknown etiology), methods used (TS or WES), number of genes and patients included, and ways of reporting data (pathogenic and likely pathogenic variants) ${ }^{26,32-37}$ Nevertheless, an overall diagnostic rate between 20 and $50 \%$ when considering only likely pathogenic variants is reported. ${ }^{38}$

Additional factors contributing to variation in overall diagnostic rate is the influence of genetic modifiers (the variants of an additional implicated gene which could either increase disease severity or could attenuate the disease manifestation) which can influence the clinical presentation of a certain phenotype. ${ }^{39}$ Combinations of variants in two or more IBTPD genes can result in phenotypes that are absent or much less severe when only one of the variants is present. In our recent study, we describe a pedigree with type 3 VWD in which a member with an additional genetic variant in SERPINC1 gene bleeds much less compared with members without that variant. ${ }^{40}$ However, extensive pedigrees or a very large number of unrelated patients are necessary to identify which affected alleles are inherited together and may serve as genetic modifiers. If the phenotype relies mainly on a laboratory phenotype, it is recommended to confirm this phenotype by a separate second analysis.

Technical limitations of the HTS technology could also contribute to the reduced overall diagnostic rate. Although next-generation sequencing remains primarily a sequencing tool that has a very high accuracy for single nucleotide changes, the use of this technique for the detection of complex rearrangements is with limitations and a second technique is required for high precision detection. A classical example, which requires a separate analysis, is intron 1 and 22 inversions in the $F 8$, pathogenic event commonly seen in severe hemophilia A. Copy number variants may also be detected with comparative analysis of read depth, but the results have to be interpreted with care. It should be mentioned that pseudogenes and repetitive elements can lead to misleading results and coverage of the noncoding space is of inadequate quality for many genes. Although the gene and pathogenic genetic variant profiles of IBTPDs are usually known, still new genes playing direct and indirect role in hemostasis are continued to be identified which could additionally affect the overall diagnostic rate. All these factors need to be considered when interpreting especially negative reports.

\section{Data Interpretation and Final Result Evaluation}

Currently, one of the largest challenges lies in the interpretation of generated sequencing data. Clinical evaluation includes an assessment of potential effects of the genetic variant(s) on the function of one or more genes and an assessment of the association of the disease to the affected gene(s). In clinical practice, the essential question to be answered is whether a gene variant adequately explains the patient's phenotype and whether the data can be used for further genetic counseling or other clinical management. To avoid incorrect interpretation and reporting, with dreadful consequences for individuals and their families, rigorous and stringent reporting standards have to be applied in the process of data evaluation. Consensus guidelines on variant interpretation and classification for clinical practice have recently been disseminated by the American College of Medical Genetics and Genomics (ACMG), the Association for Molecular Pathology (AMP), and the European Society of Human Genetics. ${ }^{41,42}$

These guidelines incorporate detailed information on the genetic variant's phenotype, mode of inheritance for the disease gene, pathogenic mechanism of the variant, protein structure and function, and evidence of the gene-disease relationship based on available literature and population data. Variants are classified according to clear rules as "pathogenic," "likely pathogenic," "uncertain significance," "likely benign," or "benign" on the basis of this information. ${ }^{41}$ One important additional recommendation is that variants of uncertain significance should not be used by clinicians for clinical decision-making. The ACMG/AMP guidelines further emphasize that variants may be reclassified and require supplementary reporting if changes in evidence concerning the variant emerge.

The genetic background of some IBDs ( $F 8, F 9, V W F$, and F7) have been extensively studied and multinational, locusspecific databases are available, where most variants will have been previously described. ${ }^{23,43-46}$ In cases of well 
known, disease-associated genes with established data on pathogenicity, using these population and genetically variant database interpretation is simple and certain. Thus, in routine clinical practice, only variants in genes that are already causally associated with disease and considered to be pathogenic on the basis of predefined criteria are routinely reported.

Many genetic variants found in patients with IBTPDs and their families are single amino acid substitutions, sometimes unique, and their relevance for the disease remains difficult to assess. In most cases, these so-called variants with uncertain significance (VUS) lead to the dysfunction of the gene and because they are rare and their impact on the function is not easy to predict, their classification into benign or pathogenic variants remains a challenge. Such variants are either not reported into databases or there is no sufficient data for the assessment of level of pathogenicity. Interpretation often begins with the assessment of variant frequency, although heavy reliance on interpreting data using allele frequency could be misleading. Another helpful tool is the use of in silico predictive pathogenicity programs (SIFT, PolyPhen2, Mutation Taster, MutPred2, Variant Effect Predictor, and SNPEff). However, the results of such computer-based algorithms can vary substantially, with contradictory interpretations compounded by the complexities of reduced penetrance, variable expressivity, mosaicism, epigenetics, modifying genes, or environmental influences. The patient's clinical presentation remains the most important context for interpreting these results. Information on familial segregation data, particularly in larger families with multiple affected individuals, can help in pathogenicity assessment of VUS. Such algorithm can facilitate the assessment in clear phenotypes and good genotype-phenotype correlation as in hemophilia A and B, factor X, and factor FXI deficiencies. On the contrary, in cases with poor genotype-phenotype correlation (factor V, VII, XII, XIII deficiencies), the interpretation of pathogenicity of VUS remains inconclusive. The evaluation of genetic variants could be even complicated from the fact that patients with the same genetic defects present different severity of the clinical symptoms.

\section{Aspects of Genetic Diagnosis in IBTPD}

- Due to the inherent complexity and the interplay between primary and secondary hemostasis, the accurate diagnosis of IBTPDs should always encompass a multidisciplinary approach.

- DNA-based analysis has become increasingly important, but to yield better conclusive results extensive anamnesis, family history, and laboratory analyses have to be provided.

- Genetic results can provide support for clinical diagnoses, modify future disease risk, and give information for therapy options.

- HTS overcomes many obstacles of traditional Sanger methods but brings new challenges that must be appreciated and systematically addressed.
Due to potential pitfalls in the interpretation of novel rare variants especially those with uncertain clinical significance, rigorous standards have to be applied in the assessment of genes and variant pathogenicity.

- High-quality, accurate variant interpretation requires scientific knowledge of the gene structure and function, the disease mechanism, and extensive clinical information about the patients' medical history.

In conclusion, genetic analysis can provide support for clinical diagnoses, modify future disease risk, and give information for therapy options and should be part of the diagnosis workup. For clinical diagnostic purposes, utilization of target sequencing panels would increase sensitivity and minimize the burden from analysis of unnecessary genes that may result in VUS. The complex interplay between primary and secondary hemostasis requires the accurate diagnosis of IBTPDs based on a multidisciplinary approach.

\section{Conflict of Interest}

The authors declare that they have no conflict of interest.

\section{References}

1 Freson K, Turro E. High-throughput sequencing approaches for diagnosing hereditary bleeding and platelet disorders. J Thromb Haemost 2017;15(07):1262-1272

2 Bastida JM, Benito R, Lozano ML, et al. Molecular diagnosis of inherited coagulation and bleeding disorders. Semin Thromb Hemost 2019;45(07):695-707

3 Sivapalaratnam S, Collins J, Gomez K. Diagnosis of inherited bleeding disorders in the genomic era. Br J Haematol 2017;179 (03):363-376

4 Quiroga T, Goycoolea M, Panes O, et al. High prevalence of bleeders of unknown cause among patients with inherited mucocutaneous bleeding. A prospective study of 280 patients and 299 controls. Haematologica 2007;92(03):357-365

5 Blanchette VS, Key NS, Ljung LR, Manco-Johnson MJ, van den Berg HM, Srivastava ASubcommittee on Factor VIII, Factor IX and Rare Coagulation Disorders of the Scientific and Standardization Committee of the International Society on Thrombosis and Hemostasis. Definitions in hemophilia: communication from the SSC of the ISTH. J Thromb Haemost 2014;12(11):1935-1939

6 Heremans J, Freson K. High-throughput sequencing for diagnosing platelet disorders: lessons learned from exploring the causes of bleeding disorders. Int J Lab Hematol 2018;40(Suppl 1):89-96

7 Ivaskevicius V, Windyga J, Baran B, et al. Phenotype-genotype correlation in eight Polish patients with inherited Factor XIII deficiency: identification of three novel mutations. Haemophilia 2007;13(05):649-657

8 Biswas A, Ivaskevicius V, Thomas A, Oldenburg J. Coagulation factor XIII deficiency. Diagnosis, prevalence and management of inherited and acquired forms. Hamostaseologie 2014;34(02): 160-166

9 Gresele P, Bury L, Falcinelli E. Inherited platelet function disorders: algorithms for phenotypic and genetic investigation. Semin Thromb Hemost 2016;42(03):292-305

10 Gresele PSubcommittee on Platelet Physiology of the International Society on Thrombosis and Hemostasis. Diagnosis of inherited platelet function disorders: guidance from the SSC of the ISTH. J Thromb Haemost 2015;13(02):314-322

11 Bastida Bermejo JM, Hernández-Rivas JM, González-Porras JR. Nuevos métodos diagnósticos en los trastornos plaquetarios hereditarios. Med Clin (Barc) 2017;148(02):71-77 
12 Bacci M, Ferretti A, Marchetti M, et al. Autoimmune disorders of platelet function: systematic review of cases of acquired Glanzmann thrombasthenia and acquired delta storage pool disease. Blood Transfus 2021. Doi: 10.2450/2021.0119-21

13 Saposnik B, Binard S, Fenneteau O, et al; French MYH9 Networka. Mutation spectrum and genotype-phenotype correlations in a large French cohort of MYH9-related disorders. Mol Genet Genomic Med 2014;2(04):297-312

14 Kruse-Jarres R, Johnsen JM. How I treat type 2B von Willebrand disease. Blood 2018;131(12):1292-1300

15 Caspers M, Pavlova A, Driesen J, et al. Deficiencies of antithrombin, protein $C$ and protein $S$ - practical experience in genetic analysis of a large patient cohort. Thromb Haemost 2012;108 (02):247-257

16 Dahlbäck B, Carlsson M, Svensson PJ. Familial thrombophilia due to a previously unrecognized mechanism characterized by poor anticoagulant response to activated protein C: prediction of a cofactor to activated protein C. Proc Natl Acad Sci U S A 1993;90 (03):1004-1008

17 Souto JC, Almasy L, Borrell M, et al. Genetic susceptibility to thrombosis and its relationship to physiological risk factors: the GAIT study. Genetic analysis of idiopathic thrombophilia. Am J Hum Genet 2000;67(06):1452-1459

18 Ageno W, Agnelli G, Imberti D, et al; MASTER Investigators. Risk factors for venous thromboembolism in the elderly: results of the master registry. Blood Coagul Fibrinolysis 2008;19(07):663-667

19 Savoia A, De Rocco D, Pecci A. MYH9 gene mutations associated with bleeding. Platelets 2017;28(03):312-315

20 Noris P, Pecci A. Hereditary thrombocytopenias: a growing list of disorders. Hematology (Am Soc Hematol Educ Program) 2017; 2017(01):385-399

21 Lambert MP. Improving interpretation of genetic testing for hereditary hemorrhagic, thrombotic, and platelet disorders. Hematology (Am Soc Hematol Educ Program) 2020;2020(01):76-81

22 Hayward CPM. How I investigate for bleeding disorders. Int J Lab Hematol 2018;40(Suppl 1):6-14

23 Peyvandi F, Menegatti M, Palla R. Rare bleeding disorders: worldwide efforts for classification, diagnosis, and management. Semin Thromb Hemost 2013;39(06):579-584

24 Oldenburg J, Ivaskevicius V, Schröder J, Müller CR, Ganguly A. Genetic background and inhibitors in previously untreated or minimally treated young patients with severe haemophilia A treated with sucrose-formulated recombinant factor VIII. Thromb Haemost 2006;95(05):903-905

25 Lentaigne C, Freson K, Laffan MA, Turro E, Ouwehand WHBRIDGEBPD Consortium and the ThromboGenomics Consortium. Inherited platelet disorders: toward DNA-based diagnosis. Blood 2016; 127(23):2814-2823

26 Bastida JM, Lozano ML, Benito R, et al. Introducing high-throughput sequencing into mainstream genetic diagnosis practice in inherited platelet disorders. Haematologica 2018;103(01): $148-162$

27 Downes K, Megy K, Duarte D, et al; NIHR BioResource. Diagnostic high-throughput sequencing of 2396 patients with bleeding, thrombotic, and platelet disorders. Blood 2019;134(23): 2082-2091

28 Megy K, Downes K, Simeoni I, et al; Subcommittee on Genomics in Thrombosis and Hemostasis. Curated disease-causing genes for bleeding, thrombotic, and platelet disorders: communication from the SSC of the ISTH. J Thromb Haemost 2019;17(08): $1253-1260$

29 Green RC, Berg JS, Grody WW, et al; American College of Medical Genetics and Genomics. ACMG recommendations for reporting of incidental findings in clinical exome and genome sequencing. Genet Med 2013;15(07):565-574
30 Clayton EW, McCullough LB, Biesecker LG, Joffe S, Ross LF, Wolf SMClinical Sequencing Exploratory Research (CSER) Consortium Pediatrics Working Group. Addressing the ethical challenges in genetic testing and sequencing of children. Am J Bioeth 2014;14 (03):3-9

31 Burke W, Antommaria AHM, Bennett R, et al. Recommendations for returning genomic incidental findings? We need to talk!. Genet Med 2013;15(11):854-859

32 Andersson NG, Rossing M, Fager Ferrari M, et al. Genetic screening of children with suspected inherited bleeding disorders. Haemophilia 2020;26(02):314-324

33 Blaauwgeers MW, van Asten I, Kruip MJHA, et al. The limitation of genetic testing in diagnosing patients suspected for congenital platelet defects. Am J Hematol 2020;95(01):E26-E28

34 Leinøe E, Gabrielaite M, Østrup O, et al. Outcome of an enhanced diagnostic pipeline for patients suspected of inherited thrombocytopenia. Br J Haematol 2019;186(02):373-376

35 Wang Q, Cao L, Sheng G, et al. Application of high-throughput sequencing in the diagnosis of inherited thrombocytopenia. Clin Appl Thromb Hemost 2018;24(9 Suppl):94S-103S

36 Andres O, König E-M, Althaus K, et al; THROMKIDplus Study Group of the Society of Paediatric Oncology Haematology (Gesellschaft für Pädiatrische Onkologie und Hämatologie, $\mathrm{GPOH}$ ) and the Society of Thrombosis Haemostasis Research (Gesellschaft für Thrombose- und Hämostaseforschung, GTH) Use of targeted high-throughput sequencing for genetic classification of patients with bleeding diathesis and suspected platelet disorder. TH Open 2018;2(04):e445-e454

37 Johnson B, Doak R, Allsup D, et al; UK GAPP Study Group. A comprehensive targeted next-generation sequencing panel for genetic diagnosis of patients with suspected inherited thrombocytopenia. Res Pract Thromb Haemost 2018;2(04):640-652

38 Ver Donck F, Downes K, Freson K. Strengths and limitations of high-throughput sequencing for the diagnosis of inherited bleeding and platelet disorders. J Thromb Haemost 2020;18(08): 1839-1845

39 Kousi M, Katsanis N. Genetic modifiers and oligogenic inheritance. Cold Spring Harb Perspect Med 2015;5(06):a017145-a017145

40 Preisler B, Pezeshkpoor B, Banchev A, et al. Familial multiple coagulation factor deficiencies (FMCFDs) in a large cohort of patients-a single-center experience in genetic diagnosis. J Clin Med 2021;10(02):347

41 Richards S, Aziz N, Bale S, et al; ACMG Laboratory Quality Assurance Committee. Standards and guidelines for the interpretation of sequence variants: a joint consensus recommendation of the American College of Medical Genetics and Genomics and the Association for Molecular Pathology. Genet Med 2015;17(05): 405-424

42 Biesecker LG, Harrison SMClinGen Sequence Variant Interpretation Working Group. The ACMG/AMP reputable source criteria for the interpretation of sequence variants. Genet Med 2018;20(12): 1687-1688

43 Pavlova A, Preisler B, Driesen J, et al. Congenital combined deficiency of coagulation factors VII and X-different genetic mechanisms. Haemophilia 2015;21(03):386-391

44 Oldenburg J, Pezeshkpoor B, Pavlova A. Historical review on genetic analysis in hemophilia A. Semin Thromb Hemost 2014; 40(08):895-902

45 Pezeshkpoor B, Pavlova A, Oldenburg J, El-Maarri O. F8 genetic analysis strategies when standard approaches fail. Hamostaseologie 2014;34(02):167-173

46 Yadegari H, Driesen J, Pavlova A, Biswas A, Hertfelder HJ, Oldenburg $J$. Mutation distribution in the von Willebrand factor gene related to the different von Willebrand disease (VWD) types in a cohort of VWD patients. Thromb Haemost 2012;108(04):662-671 